\title{
Chapter 3 \\ Climate Change and Infectious Livestock Diseases: The Case of Rift Valley Fever and Tick-Borne Diseases
}

\author{
Bernard Bett, Johanna Lindahl, and Grace Delia
}

\subsection{Background}

The global-average surface temperature has risen steadily since the nineteenth century due to an increase in the concentration of heat-trapping gases such as carbon dioxide and methane in the atmosphere. These changes have had important consequences on rainfall patterns, the intensity of droughts, and the viability of ecosystems (Martin et al. 2008) among other changes. Taken together, these changes have substantial effects on the transmission patterns of infectious diseases.

A few studies have been done to identify processes through which climate change influences infectious disease occurrence. While more work needs to be done to fully characterise these processes, the existing knowledge suggests two broad categories of impact, often classified as 'direct' and 'indirect'. Direct impacts are realised when a rise in temperature, precipitation intensity, flooding, humidity, etc. increase pathogens' or vectors' metabolic processes, reproductive rates, and (or) population densities, resulting in enhanced vector-pathogen-host contact and, therefore, the risk of disease (Bett et al. 2017). These changes operate within defined biological limits. This is because an increase in temperature or flooding beyond a given threshold leads to the desiccation of these arthropods or the flushing of vector breeding sites, and hence a decline in disease transmission risk. Direct effects are often associated with diseases caused by pathogens that spend part of their life cycles outside

\author{
B. Bett $(\triangle) \cdot$ G. Delia \\ International Livestock Research Institute, Nairobi, Kenya \\ e-mail: b.bett@cgiar.org; d.grace@cgiar.org \\ J. Lindahl \\ International Livestock Research Institute, Nairobi, Kenya \\ Uppsala University, Uppsala, Sweden
}

Swedish University of Agricultural Sciences, Uppsala, Sweden

e-mail: J.Lindahl@cgiar.org 
a mammalian host. These include vector-borne diseases, helminthoses and fungal infections.

Indirect effects are less apparent and would include changes in disease transmission patterns associated with climate-induced ecological, socio-cultural or behavioural disruptions. In pastoral areas, for example, prolonged droughts trigger more frequent and long-distance movements which enhance contact between distinct populations of animals. This would also include movement into previously uninhabited areas potentiating exposure to new disease agents. Different indirect effects are reviewed in Lindahl and Grace (2015).

We use two well-studied vector-borne diseases-Rift Valley fever, which often occurs in epidemics in East Africa, and tick-borne diseases, which are endemic in many parts of the world - to demonstrate the impacts of climate change on livestock diseases. Our review focuses on the direct effects given that indirect effects are not well studied and are also difficult to quantify.

\subsection{Case Studies}

\subsubsection{Rift Valley Fever}

Rift Valley fever (RVF) is a mosquito-borne viral zoonosis mainly affecting sheep, goats, cattle, buffaloes and camels. People become infected following a bite from an infected mosquito, or after close contact with acutely infected animals or infected tissues. In people, the disease manifests as a mild influenza-like syndrome in a majority of cases (more than $80 \%$ ) or a severe disease with haemorrhagic fever, encephalitis, or retinitis in a few cases (Njenga et al. 2009). In livestock, the disease manifests as increased abortion and perinatal mortality rates.

\subsubsection{Drivers}

RVF outbreaks have been reported in some countries in East and southern Africa including Kenya, South Africa, Tanzania and Uganda following periods of abovenormal precipitation. The disease has also been reported in other countries including the Comoros archipelago, Madagascar, Mauritania, Saudi Arabia, Senegal and Sudan (Madani et al. 2003) and Yemen (Abdo-Salem et al. 2006). In South Africa, recent RVF outbreaks observed in 2008-2011 were associated with relentless and widespread strong seasonal rainfall and high soil saturation (Williams et al. 2016). Areas affected by these outbreaks are shown in Fig. 3.1. In East Africa, major outbreaks are often associated with the warm phase of the El Niño/Southern Oscillation (ENSO) phenomenon, although there have been a few incidences (e.g. in mid-1989) when an elevated RVF activity was not ENSO-driven. There have also been localised outbreaks in Uganda associated with seasonal rainfall and flooding. Figure 3.2 

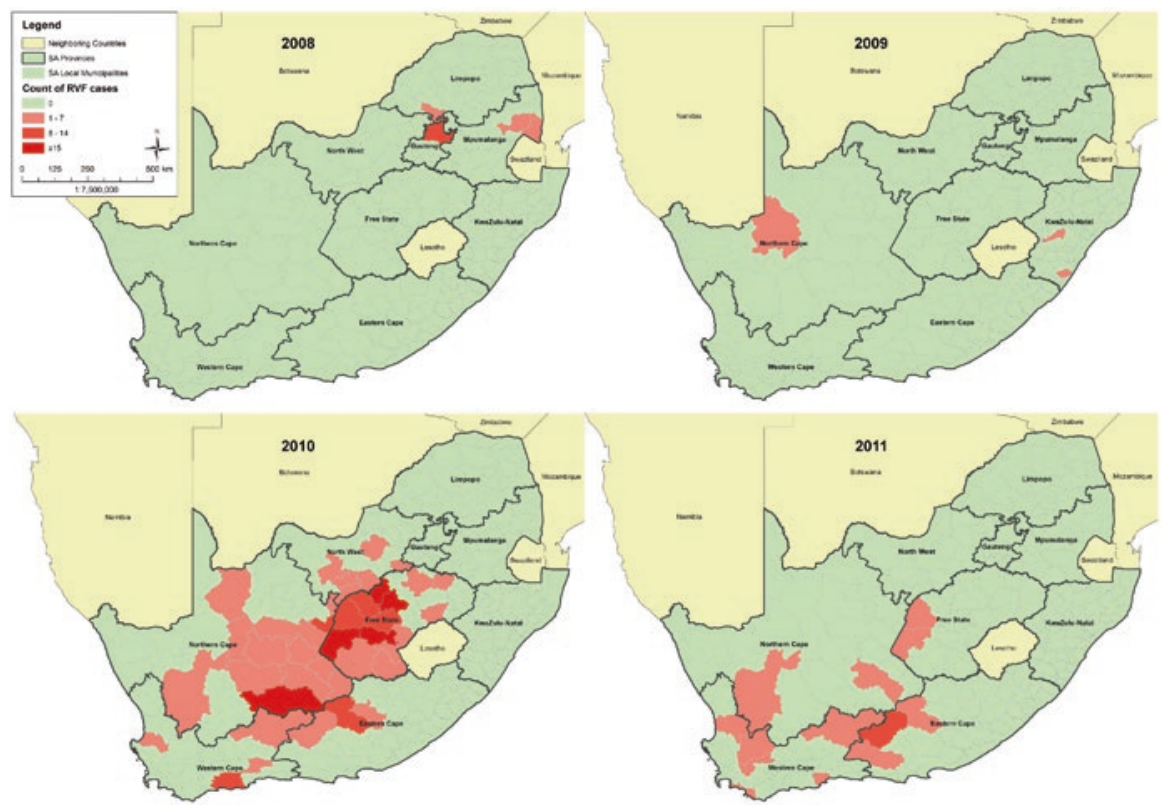

Fig. 3.1 The spatial distribution of laboratory-confirmed human cases in South Africa in local administrative municipalities 2008-2011 (Archer et al. 2013). The spatiotemporal distribution of the RVF cases in humans paralleled those of livestock, which were triggered by heavy rainfall

gives an RVF risk map based on data that were collected during the 2006/2007 outbreak. Not all El Niño events lead to RVF outbreaks; El Niño events recorded in Kenya in 1964, 1969, 1972-1973, 1981 and 1991-1995, for example, did not lead to RVF outbreaks.

In West Africa, RVF outbreaks occurred in 1998, 2003, 2010 and 2012 following an interlude between a dry period, lasting for about a week, and a period of heavy precipitation (Caminade et al. 2014). The 2009-2010 outbreak, which affected small ruminants, camels and people was associated with a fourfold increase in rainfall in a desert region in northern Mauritania (Faye et al. 2014). Similar outbreaks occurred in Senegal in 2013-2014, exacerbated by extensive livestock movements that aided the dissemination of the virus (Sow et al. 2016).

\subsubsection{Climate Change and RVF}

A few studies have been done to evaluate the expected impacts of climate change on RVF transmission. These suggest that climate change is likely to expand RVF's geographical range due to expansion of the vector niches (Mweya et al. 2017; Taylor et al. 2016). There are also indications that the average rainfall in eastern Africa, including the Horn of Africa, is expected to increase, while that for southern Africa is likely to decline with climate change (Conway 2009). ENSO-related precipitation 


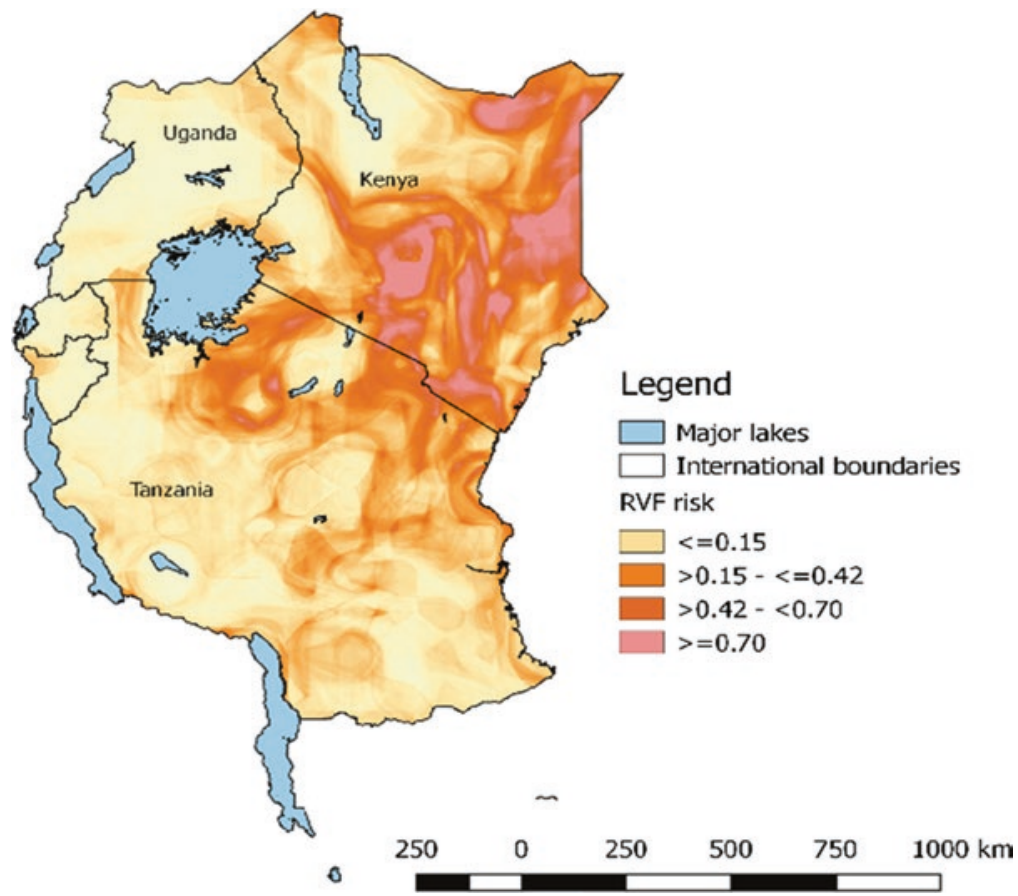

Fig. 3.2 Risk map for RVF in East Africa based on reported cases in livestock during the 2006/2007 outbreak and rainfall distribution (Bett et al. 2017). Probability estimates given on the map indicate the chance that a given area could experience an RVF outbreak based on the environmental conditions observed in December 2006

variability is also predicted to intensify (Intergovernmental Panel on Climate Change 2014) and this might have stronger implications for RVF, given that the intense precipitation which drives an RVF epidemic follows El Niño and La Niña events in East and South Africa, respectively. Further evidence for an increased precipitation under intermediate warming scenarios in parts of equatorial East Africa is provided by Hulme et al. (2001). They suggest that the region will experience a 5-20\% increase in rainfall between December and February and 5-10\% reduction in rainfall between June and August by 2050.

Climate change may indirectly increase RVF risk through land use change associated with the development of irrigation schemes and dams. The increasing frequency of droughts and erratic rainfall in arid and semi-arid areas would necessitate the construction of dams and irrigation schemes to support water supply and food production. Previously, outbreaks of RVF have been reported following flood irrigation in the Orange River region and Western Cape province, South Africa (Williams et al. 2016), and the construction of dams, i.e. Aswan High Dam in Egypt in 1977 
and the Senegal Dam on the Senegal-Mauritania border in 1987/1988 (Martin et al. 2008). A recent study conducted in Kenya confirmed that irrigated areas in arid and semi-arid areas support endemic transmission of RVF (Mbotha et al. 2017) but more work is needed to isolate the virus from such cases to confirm observations made from serological studies. Drought-resistant livestock species, including goats, which are thought to play a critical role in the epidemiology of RVF and other zoonotic diseases, are increasingly being raised in arid and semi-arid areas as one of the adaptation measures for climate change and variability. These changes are likely to increase the risk of infectious diseases that would compromise health and livelihoods of a large population of pastoralists.

\subsubsection{Ticks and Tick-Borne Diseases (TBDs)}

Ticks are important vectors of a wide range of pathogens that cause many diseases in livestock such as anaplasmosis, babesiosis, cowdriosis, coxiellosis (Q fever), Crimean-Congo haemorrhagic fever, ehrlichiosis and theileriosis. East Coast fever (ECF) - the disease with the greatest economic importance in dairy animals-is caused by Theileria parva and transmitted by Rhipicephalus appendiculatus. The disease causes high mortality, especially in highly productive, susceptible breeds where mortality can reach $100 \%$. Other losses associated with the disease include poor weight gain, fertility losses, reduced growth and productivity, paralysis and increased susceptibility to other diseases. Its geographical range stretches from South Sudan to South Africa and up to Democratic Republic of the Congo (DRC) (Olwoch et al. 2008).

There are few studies in East and southern Africa that have looked at the effects of climate change on ticks and TBDs. Olwoch et al. (2008) applied a simple climate envelope model to investigate the effects of climate change on the distribution of $R$. appendiculatus and ECF in sub-Saharan Africa, based on climate anomalies for 2020 s versus 1990s. They predicted a reduction in the range of the tick in the western arid regions in Angola, southern DRC and Namibia, given that these areas were already hot and dry and further increases in temperature would make them unsuitable under the future climate scenarios used. On the contrary, the study established that some areas in Botswana, eastern DRC, the Northern and Eastern Cape provinces of South Africa, and Zambia would become more suitable in the 2020s, because of increased rainfall and a rise in the minimum temperatures.

From a global perspective, a rise in temperature has the potential to expand the geographical range of about $50 \%$ of tick species, with $70 \%$ of these involving economically important tick species (Cumming and van Vuuren 2006). This mainly represents the northern expansion of the northern limits of ticks as has been observed in Sweden and Russia among other places. 


\subsubsection{Inferences from the Case Studies}

These two cases show that climate change will cause local shifts in geographical ranges of most vector-borne diseases in both dry/hot and cool/wet areas due to at least two distinct processes. In the hot/dry areas, scenarios of higher rainfall and humidity would promote higher survival rates of vectors, while in the cool/wet areas, increasing temperatures would allow overwintering of these vectors. The key determinants of vectors' population dynamics include temperature, humidity and water availability, especially for mosquitoes. Although we point to potential shifts in disease risk, we believe climate change would affect transmission patterns of infectious diseases in multiple ways, including lowering the effectiveness of existing intervention strategies. No studies have been done to verify this issue but given that the rate of development of most arthropods would increase with temperature and lead to changing population dynamics, the frequency of application of some of the vector control measures such as acaricides might need to be reviewed. High temperatures also reduce the hosts' immune responses (Dittmar et al. 2014) and studies need to be done to determine whether this has implications on the effectiveness of the available vaccines which confer protection by priming the hosts' immune system.

\subsection{Mitigations and Adaptations}

Projections from simulation models suggest that global warming will continue to worsen if the current levels of greenhouse gas emissions are not reduced. It is, therefore, expected that the incidence and impacts of climate-sensitive diseases-including RVF and TBDs-will increase, particularly among the most vulnerable populations in developing countries. These diseases, though, can be mitigated by established control measures including quarantine, import bans, the identification and removal of suspicious animals and premises, surveillance and reporting, vaccination, disinfection, and compensation (Grace and McDermott 2012). However, the effectiveness of some of these measures in the face of climate change has not been determined. Moreover, their deployment is inadequate as the animal health systems in most of these countries have deteriorated.

Vector control and vaccination are often used to control RVF and TBDs. Vector control is however not a reliable measure for controlling RVF in livestock (Gachohi et al. 2017). This is because floods that trigger RVF epidemics maintain high mosquito population densities and insecticide-induced mortality rates would be much lower compared to the rates of development and emergence of new adults. Conversely, acaricides have been used successfully for many years to control TBDs but recent observations indicate that tick resistance to acaricides is threatening to limit the effectiveness of this measure. Alternative ways of managing TBDs are therefore being developed, such as the use of tick vaccines (specifically for 
Boophilus spp.), immunisation of animals through infection-and-treatment methods (ITM), breeding of TBD-resistant animals, and the strategic use of acaricides to balance the need to eliminate ticks versus the need to raise the endemic stability of TBDs in the livestock populations. There are ongoing studies to develop new vaccines to replace ITM.

RVF can be reliably controlled using livestock vaccination but its episodic occurrence, a predilection for remote, pastoral areas and lack of forward planning and pre-allocation of emergency funds in most animal health institutions cause a lot of delays in response. An assessment of emergency vaccination programmes that were implemented following the 2006/2007 outbreak in Kenya (Gachohi et al. 2012) as well as those deployed during the recent RVF scare in 2016/2017 showed that livestock vaccination was implemented late and at very low levels to attain sustainable herd immunity. It has now been realised that the administration of livestock vaccination as part of emergency response measures during periods of heightened RVF risk does not provide beneficial outcomes. They fall short of achieving critical levels of coverage that are required for the establishment of protective immunity. Research is underway to determine alternative vaccination strategies for RVF that might involve periodic vaccination in the high-risk areas in place of reactive or emergency vaccinations. In this case, reactive vaccinations can be used strategically to complement periodic vaccination following warnings for El Niño in East Africa or La Niña in South Africa.

Animal health programmes need to be underpinned by efficient surveillance systems which promptly detect and report disease occurrence patterns for action, and guide the prioritisation of interventions to geographical regions or periods where/ when interventions can yield desirable outcomes. There have been multiple uncoordinated efforts towards improving disease surveillance and the development of risk maps and contingency plans in the target areas to help in rationalising interventions. New surveillance systems based on citizen science methods and cloud computing offer great opportunities for identifying the distribution of these infectious diseases; they might also provide clues on how to deploy measures for multiple diseases at the same time. In addition, these systems can be programmed to provide input data for real-time disease forecasting, enabling decision-makers to plan more effectively for impending disease risks. This would require analysing such surveillance data with climate and land use/land cover data as predictors to generate dynamic risk maps.

\subsection{Conclusions and Implications for Development}

Climate change is expected to increase the risk of many vector-borne diseases, including those of RVF and TBDs. It is also likely to reduce the effectiveness of some of the control measures-such as vector control efforts-and hence decision makers need to be sensitized more on how to make the best use of the existing interventions, as more research is implemented to determine optimal control options. A 
key trend of recent decades has been the greater integration of human and veterinary medicine. One World One Health is a growing movement built around the premise that the health of humans, animals and the environment are inextricably linked, and that disease is best managed in broad and interdisciplinary collaborations. Such a multidisciplinary approach can improve targeting of interventions.

\section{References}

Abdo-Salem S, Gerbier G, Bonnet P et al (2006) Descriptive and spatial epidemiology of Rift Valley fever outbreak in Yemen 2000-2001. Ann N Y Acad Sci 1081:240-242. https://doi. org/10.1196/annals.1373.028

Archer BN, Thomas J, Weyer J et al (2013) Epidemiologic investigations into outbreaks of Rift Valley fever in humans, South Africa, 2008-2011. Emerg Infect Dis 19:1918-1925. https://doi. org/10.3201/eid1912.121527

Bett B, Kiunga P, Gachohi J et al (2017) Effects of climate change on the occurrence and distribution of livestock diseases. Prev Vet Med. https://doi.org/10.1016/j.prevetmed.2016.11.019

Caminade C, Ndione JA, Diallo M et al (2014) Rift Valley fever outbreaks in Mauritania and related environmental conditions. Int J Environ Res Public Health 11:903-918. https://doi. org/10.3390/ijerph110100903

Conway G (2009) The science of climate change in Africa: impacts and adaptation. Imperial College, London

Cumming G, van Vuuren D (2006) Will climate change affect ectoparasite species ranges? Glob Ecol Biogeogr 15:486-497

Dittmar J, Janssen H, Kuske A et al (2014) Heat and immunity: an experimental heat wave alters immune functions in three-spined sticklebacks (Gasterosteus aculeatus). J Anim Ecol 83:744757. https://doi.org/10.1111/1365-2656.12175

Faye O, Ba H, Ba Y et al (2014) Reemergence of Rift Valley fever, Mauritania, 2010. Emerg Infect Dis 20:300-303. https://doi.org/10.3201/eid2002.130996

Gachohi JM, Bett B, Njogu G et al (2012) The 2006-2007 Rift Valley fever outbreak in Kenya: sources of early warning messages and response measures implemented by the Department of Veterinary Services. Rev Sci Tech 31:877-887

Gachohi JM, Njenga MK, Kitala P et al (2017) Correction: modelling vaccination strategies against Rift Valley fever in livestock in Kenya. PLoS Negl Trop Dis 11:e005316. https://doi. org/10.1371/journal.pntd.0005316

Grace D, McDermott J (2012) Livestock epidemic. In: Wisner B, Gaillard JC, Kelman I (eds) Handbook of hazards and disaster risk reduction and management. Routledge, London

Hulme M, Doherty R, Ngara T et al (2001) African climate change: 1900-2100. Clim Res 17:145-168

Intergovernmental Panel on Climate Change (2014) Synthesis report. In: Pachauri RK, Meyer LA (eds) Contribution of working groups I, II and III to the fifth assessment report of the IPCC. IPCC, Geneva

Lindahl JF, Grace D (2015) The consequences of human actions on risks for infectious diseases: a review. Infect Ecol Epidemiol 5:30048. https://doi.org/10.3402/iee.v5.30048

Madani TA, Al-Mazrou YY, Al-Jeffri MH et al (2003) Rift Valley fever epidemic in Saudi Arabia: epidemiological, clinical, and laboratory characteristics. Clin Infect Dis 37:1084-1092. https:// doi.org/10.1086/378747

Martin V, Chevalier V, Ceccato P et al (2008) The impact of climate change on the epidemiology and control of Rift Valley fever vector-borne diseases Rift Valley fever and climate change. Rev Sci Technol Off Int Epiz 27:413-426 
Mbotha D, Bett B, Kairu-Wanyoike S et al (2017) Inter-epidemic Rift Valley fever virus seroconversions in an irrigation scheme in Bura, south-east Kenya. Transbound Emerg Dis. https://doi. org/10.1111/tbed.12674

Mweya CN, Mboera LEG, Kimera SI (2017) Climate influence on emerging risk areas for Rift Valley fever epidemics in Tanzania. Am J Trop Med Hyg 97:109-114. https://doi.org/10.4269/ ajtmh.16-0444

Njenga MK, Paweska J, Wanjala R et al (2009) Using a field quantitative real-time PCR test to rapidly identify highly viremic Rift Valley fever cases. J Clin Microbiol 47:1166-1171. https:// doi.org/10.1128/JCM.01905-08

Olwoch JM, Reyers B, Engelbrecht FA et al (2008) Climate change and the tick-borne disease, Theileriosis (East Coast fever) in sub-Saharan Africa. J Arid Environ 72:108-120. https://doi. org/10.1016/j.jaridenv.2007.04.003

Sow A, Faye O, Ba Y et al (2016) Widespread Rift Valley fever emergence in Senegal in 20132014. Open Forum Infect Dis 3:ofw149. https://doi.org/10.1093/ofid/ofw149

Taylor D, Hagenlocher M, Jones AE et al (2016) Environmental change and Rift Valley fever in eastern Africa: projecting beyond healthy futures. Geospat Health 11:387. https://doi. org/10.4081/gh.2016.387

Williams R, Malherbe J, Weepener $\mathrm{H}$ et al (2016) Anomalous high rainfall and soil saturation as combined risk indicator of Rift Valley fever outbreaks, South Africa, 2008-2011. Emerg Infect Dis 22. https://doi.org/10.3201/eid2212.151352

Open Access This chapter is licensed under the terms of the Creative Commons Attribution 4.0 International License (http://creativecommons.org/licenses/by/4.0/), which permits use, sharing, adaptation, distribution and reproduction in any medium or format, as long as you give appropriate credit to the original author(s) and the source, provide a link to the Creative Commons license and indicate if changes were made.

The images or other third party material in this chapter are included in the chapter's Creative Commons license, unless indicated otherwise in a credit line to the material. If material is not included in the chapter's Creative Commons license and your intended use is not permitted by statutory regulation or exceeds the permitted use, you will need to obtain permission directly from the copyright holder.

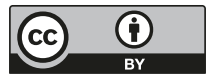

